\title{
Some Properties of Glutathione Biosynthesis-deficient Mutants of Escherichia coli B
}

\author{
By KOUSAKU MURATA* AND AKIRA KIMURA \\ Research Institute for Food Science, Kyoto University, Uji, Kyoto 611, Japan
}

(Received 15 June 1981; revised 25 September 1981)

\begin{abstract}
Mutants of Escherichia coli B that contain essentially no detectable glutathione were isolated. These mutants had a very low activity of $\gamma$-glutamylcysteine synthetase or glutathione synthetase. No significant differences in growth in minimal medium were observed between the mutants and the parental strain. The mutants lacking $\gamma$-glutamylcysteine synthetase activity were more susceptible to toxic compounds than either the parental strain or a glutathione synthetase-deficient strain. The mutants lacking $\gamma$-glutamylcysteine synthetase activity were also susceptible to oxygen.
\end{abstract}

\section{INTRODUCTION}

We have been studying the metabolism of glutathione in order to elucidate its functions in Escherichia coli $\mathrm{B}$. One way of doing this is to observe the effect of the intracellular oxidation of glutathione by chemical agents such as diamide (Kosower et al., 1969), azoester (methylphenyldiazene carboxylate) or $t$-butyl hydroperoxide (Srivastava et al., 1974). These agents have been shown to be effective in oxidizing intracellular glutathione, but in many cases they also cause a reduction in cell viability. Therefore, in studying the functions of glutathione in cells, it would be advantageous to use mutants deficient in glutathione biosynthesis. Recently, we developed an efficient method for isolating such mutants of $E$. coli $B$ and have obtained mutants deficient in the activity of $\gamma$-glutamylcysteine synthetase or glutathione synthetase (Murata et al., 1981). This paper reports the properties of the mutants and the physiological functions of glutathione in $E$. coli B.

\section{METHODS}

Chemicals. Reduced and oxidized glutathione and acetyl phosphate were purchased from Sigma. $\gamma$-Glutamylcysteine was prepared by the method of Strumeyer \& Block (1962). All other chemicals were analytical grade reagents.

Bacterial strains, culture conditions and preparation of cell extracts. The strains used and their properties are listed in Table 1. All strains were grown in the minimal medium of Davis \& Mingioli (1950), with or without nutritional supplements or other chemicals as indicated. Glucose was autoclaved separately. Other culture conditions and the preparation of cell extracts were as previously described (Murata et al., 1980). Protein was determined by the Lowry method.

Isolation of mutants. The glutathione biosynthesis-deficient mutants were isolated by the method described previously (Murata et al., 1981). Revertants of the $\gamma$-glutamylcysteine synthetase-deficient strain C912 were isolated by the following procedure. Cells were treated with $N$-methyl- $N^{\prime}$-nitro- $N$-nitrosoguanidine (NTG) by the method of Adelberg et al. (1965). Incubation was carried out with $200 \mu \mathrm{g} \mathrm{NTG} \mathrm{ml} \mathbf{l}^{-1}$ at $30^{\circ} \mathrm{C}$ for $30 \mathrm{~min}$. After the treatment, cells were washed with water and then suspended in L-broth [comprising $1.0 \%(\mathrm{w} / \mathrm{v})$ polypeptone, $0.5 \%(\mathrm{w} / \mathrm{v}) \mathrm{NaCl}, 0.5 \%(\mathrm{w} / \mathrm{v})$ yeast extract and $0.1 \%(\mathrm{w} / \mathrm{v})$ glucose $(\mathrm{pH} 7.2)]$. The culture was grown at $37^{\circ} \mathrm{C}$ for several hours to allow expression of the phenotype. After washing with saline solution, cells were spread on agar plates of minimal medium supplemented with $10 \mu \mathrm{g} 8$-hydroxyquinoline $\mathrm{ml}^{-1}$. Plates were incubated at $37^{\circ} \mathrm{C}$ for $2 \mathrm{~d}$ and then the colonies were tested for their ability to synthesize $\gamma$-glutamylcysteine by the method of Jackson (1969). One of the revertants was designated RC912. 
Table 1. Escherichia coli B strains used

\begin{tabular}{|c|c|c|}
\hline Strain & Parent & Relevant properties* \\
\hline 355 & - & Wild-type \\
\hline M71 & 355 & $\mathrm{Cys}^{-}$ \\
\hline M910 & M71 & $\mathrm{Mg}^{\mathrm{R}}$ \\
\hline $\mathrm{C} 912$ & M910 & $\mathrm{Mg}^{\mathrm{R}}, \mathrm{Gsh}^{-}$ \\
\hline C915 & M910 & $\mathrm{Mg}^{\mathrm{R}}, \mathrm{G} \operatorname{sh} \mathrm{A}^{-}$ \\
\hline RC912 & C 912 & $\mathrm{Mg}^{\mathrm{R}}$ \\
\hline C 1001 & M910 & $\mathrm{Mg}^{\mathrm{R}}, \mathrm{Gsh}^{-}$ \\
\hline
\end{tabular}

${ }^{*} \mathrm{Cys}^{-}$, requirement for cysteine; $\mathrm{Mg}^{\mathrm{R}}$, resistant to methylglyoxal; GshA ${ }^{-}$, deficient in $\gamma$-glutamylcysteine synthetase activity; $\mathrm{GshB}^{-}$, deficient in glutathione synthetase activity.

Enzyme assays. The activities of $\gamma$-glutamylcysteine synthetase (EC 6.3.2.2) and glutathione synthetase (EC 6.3.2.3) were determined by the methods of Jackson (1969) and Mooz \& Meister (1967), respectively.

Determination of intracellular concentrations of glutathione and total thiol compounds. Cells growing exponentially in minimal medium were harvested and washed once with cold $0.85 \%(\mathrm{w} / \mathrm{v})$ saline solution. Ethanol $(3.0 \mathrm{ml} ; 80 \%, \mathrm{w} / \mathrm{v})$ was added to $0.5 \mathrm{~g}$ wet wt cells and the thiol compounds were extracted by boiling for $5 \mathrm{~min}$. The clear supernatant obtained after centrifugation was used for the determination of glutathione, as described by Murata et al. (1978), and total thiol compounds, by titration with Ellman's reagent (Ellman, 1959). All results were expressed as $\mu$ mol glutathione or thiol compounds ( $\mathrm{g}$ wet wt cells $)^{-1}$.

Determination of minimum inhibitory concentrations. The gradient plate technique of Szybalsky \& Bryson (1952) was used. The method employed a press-bottom Petri plate $(10 \mathrm{~cm}$ diam.) with two layers of agar. The lower layer, consisting of $10 \mathrm{ml}$ minimal agar medium, was allowed to harden with the plate slanted to cover the entire bottom. The second layer, consisting of $10 \mathrm{ml}$ minimal agar medium containing an appropriate concentration $\left(C_{0}, \mu \mathrm{g} \mathrm{ml}^{-1}\right)$ of the test compound, was added with the plate in the normal horizontal position. The plates were incubated at $37^{\circ} \mathrm{C}$ for $24 \mathrm{~h}$ after streaking with cells. The length of the growing streak $(L, \mathrm{~cm})$ was measured and the minimum inhibitory concentration $\left(C, \mu \mathrm{g} \mathrm{ml}^{-1}\right)$ was calculated using the equation: $C=L C_{0} / 10$.

Survival curves. Cells growing exponentially in minimal medium were harvested and resuspended in $3.0 \mathrm{ml}$ minimal medium containing the test compound at a density of $5 \times 10^{8}$ cells ml-1. The suspension was incubated at $37^{\circ} \mathrm{C}$ with shaking. At appropriate intervals, samples were taken, diluted, and spread on L-broth agar plates. The plates were incubated at $37^{\circ} \mathrm{C}$ to determine the number of surviving cells.

\section{RESULTS}

Activities of enzymes involved in glutathione biosynthesis. The activities of $\gamma$ glutamylcysteine synthetase and glutathione synthetase were determined to locate the step in glutathione biosynthesis which was blocked in the mutant strains (Table 2). As reported previously (Murata et al., 1981), strains C912 and C915 were deficient in $\gamma$-glutamylcysteine synthetase activity. Strain C1001 lacked glutathione synthetase activity. Strain RC912, a revertant of $\mathrm{C} 912$, had fully recovered the activity of $\gamma$-glutamylcysteine synthetase.

Intracellular concentrations of glutathione and total thiol compounds. The amounts of intracellular glutathione and total thiol compounds in the mutant and parental strains were determined (Table 3). In the parental strains (355 and M910), glutathione represents about $35-40 \%$ of the total thiol compounds. As suggested previously (Murata et al., 1980), methylglyoxal resistance was associated with an increase in the contents of glutathione and total thiol compounds. In the mutant strains (C912 and C1001), no significant amount of glutathione was detected. Higher concentrations of glutathione and total thiol compounds were found in RC912, a revertant of mutant C912.

Growth in minimal medium. Figure 1 shows that the maximum levels of growth of the mutant strains in minimal medium were somewhat lower than that of the parental strain. The addition of glutathione to the medium did not improve the growth of strain C912.

Susceptibility to inhibitors. The susceptibility of the mutant strains to various chemicals was investigated, since glutathione is thought to be responsible for the detoxification of 
Table 2. Activities of $\gamma$-glutamylcysteine synthetase and glutathione synthetase in mutant and parental strains

$\begin{array}{llcc}\text { Strain } & \text { Parent } & \begin{array}{c}\gamma \text { Glutamylcysteine } \\ \text { synthetase } \\ \text { [nmol min } \\ \text { (mg protein) }^{-1} \text { ] }\end{array} & \begin{array}{c}\text { Glutathione } \\ \text { synthetase } \\ \text { [nmol min }\end{array} \\ \text { (mg protein) } \\ \text { C900 } & \text { M910 } & 22.1 & 26.8 \\ \text { C912 } & \text { M910 } & 0.00 & 24.9 \\ \text { C915 } & \text { M910 } & 0.02 & 26.9 \\ \text { C964 } & \text { M910 } & 21.9 & 23.9 \\ \text { C1001 } & \text { M910 } & 24.9 & 0.01 \\ \text { C1065 } & \text { M910 } & 23.4 & 24 \cdot 8 \\ \text { C1198 } & \text { M910 } & 22.3 & 23.8 \\ \text { RC912 } & \text { C912 } & 24.8 & 23.7 \\ \text { 355 } & \text { Wild } & 14.2 & 16.2 \\ \text { M910 } & 355 & 23.8 & 24.9\end{array}$

Table 3. Glutathione and total thiol contents of mutant and parental strains

$\begin{array}{lccc}\text { Strain } & \begin{array}{c}\text { Susceptibility to } \\ \text { methylglyoxal }\end{array} & \begin{array}{c}\text { Total thiol } \\ {\left[\mu \mathrm{mol}(\mathrm{g} \text { cells })^{-1}\right]}\end{array} & \begin{array}{c}\text { Glutathione } \\ {\left[\mu \mathrm{mol}(\mathrm{g} \text { cells })^{-1}\right]}\end{array} \\ 355 & \text { Sensitive } & 8 \cdot 2 & 2.9 \\ \text { M910 } & \text { Resistant } & 9.6 & 3.8 \\ \text { C912 } & \text { Resistant } & 3.9 & 0.04 \\ \text { C1001 } & \text { Resistant } & 4.9 & 0.02 \\ \text { RC912 } & \text { Resistant } & 10.7 & 4.7\end{array}$

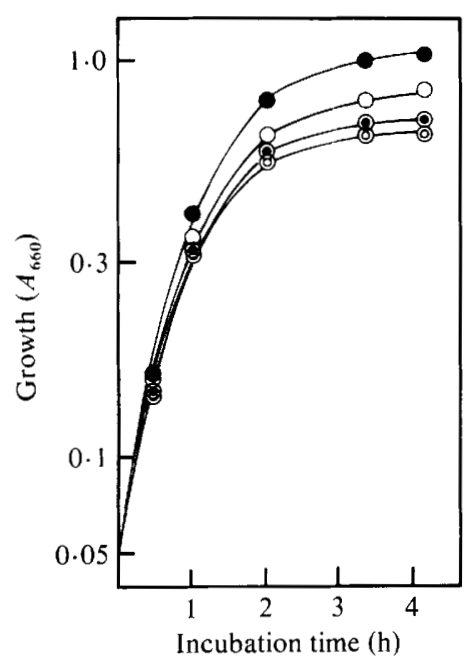

Fig. 1

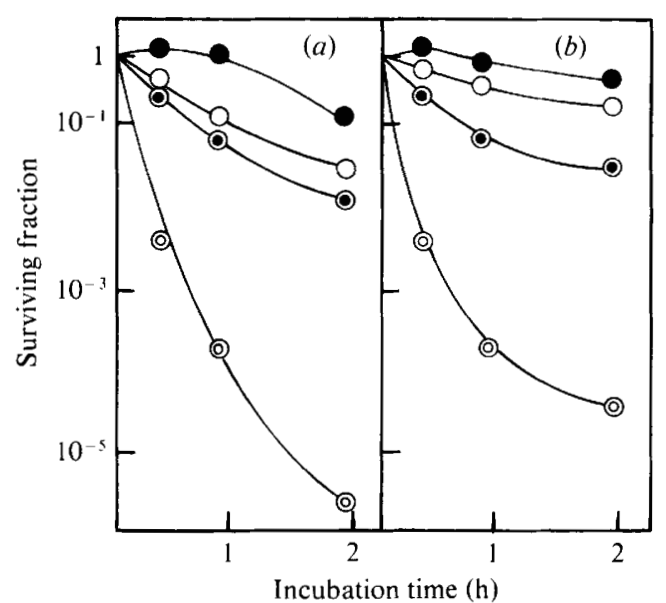

Fig. 2

Fig. 1. Growth of mutant and parental strains in minimal medium. Overnight cultures in minimal medium were harvested and washed once with $0.85 \%$ saline solution. Samples of cells were resuspended in $3.0 \mathrm{ml}$ minimal medium (supplemented with $0.1 \mathrm{~mm}$-glutathione where indicated) and incubated at $37^{\circ} \mathrm{C}$ with shaking. Growth was monitored by measurement of the absorbance at $660 \mathrm{~nm}$ as described previously (Murata et al., 1980). Strains: O, M910; O, C1001; ๑, C912; O, C912+ $0.1 \mathrm{~mm}$-glutathione.

Fig. 2. Decrease in cell viability during incubation in the presence of TMTD $(a)$ and 8-HQ (b). Cells growing exponentially in minimal medium were harvested, washed once with $0.85 \%$ saline solution and resuspended in $3.0 \mathrm{ml}$ minimal medium containing $50 \mu \mathrm{g} \mathrm{TMTD} \mathrm{m} l^{-1}$ or $40 \mu \mathrm{g} 8-\mathrm{HQ} \mathrm{ml} \mathrm{Tl}^{-1}$ (and supplemented with $0.1 \mathrm{~mm}$-glutathione where indicated). The incubation was at $37^{\circ} \mathrm{C}$ with shaking. The number of viable cells after each treatment was determined by counting the colonies that appeared on nutrient agar plates as described in the Methods. Strains: O, M910; O, C1001; O, C912; O, C912 +0.1 mM-glutathione. 
Table 4. Minimum inhibitory concentrations of various compounds

\begin{tabular}{|c|c|c|c|c|}
\hline \multirow[b]{2}{*}{ Compound } & \multicolumn{4}{|c|}{ Minimum inhibitory concentration $\left(\mu \mathrm{g} \mathrm{ml}^{-1}\right)$} \\
\hline & 355 & M910 & $\mathrm{C} 912$ & $\mathrm{C} 1001$ \\
\hline $\mathrm{HgCl}_{2}$ & $4 \cdot 0$ & $5 \cdot 0$ & 0.1 & 0.4 \\
\hline Iodoacetamide & 75 & 92 & 20 & 40 \\
\hline Tetramethylthiuram disulphide (TMTD) & 90 & 100 & $5 \cdot 5$ & 10 \\
\hline 8-Hydroxyquinoline (8-HQ) & 15 & 20 & $4 \cdot 0$ & 10 \\
\hline Propyl 4-hydroxybenzoate & 95 & 120 & 40 & 75 \\
\hline Methylglyoxal & 25 & 40 & $5 \cdot 5$ & $7 \cdot 5$ \\
\hline Chloramphenicol & $3 \cdot 5$ & $4 \cdot 0$ & $8 \cdot 0$ & $8 \cdot 5$ \\
\hline Dibromophenol & 120 & 140 & 75 & 85 \\
\hline$m$-Cresol & 1000 & 1000 & 900 & 1000 \\
\hline Tetrabromo- $m$-cresol & 500 & 550 & 50 & 120 \\
\hline Thymol & 250 & 300 & 150 & 200 \\
\hline Tetrabromophenolphthalein & 95 & 130 & 55 & 75 \\
\hline Chloromethylketone & 250 & 250 & 80 & 110 \\
\hline
\end{tabular}

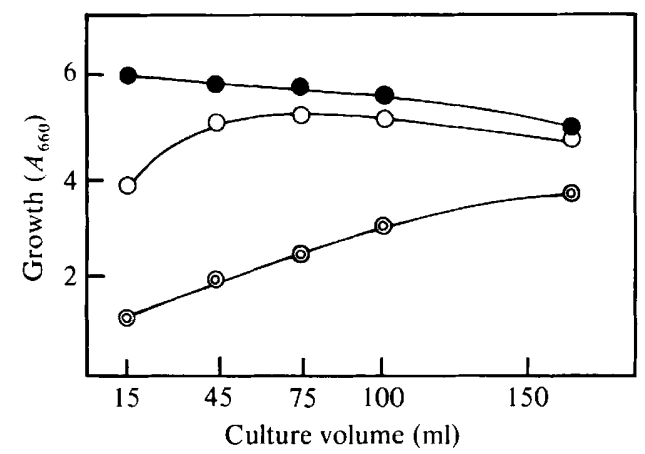

Fig. 3. Effect of culture volume on the growth of mutant and parental strains. Cells were grown in various volumes of minimal medium containing $10 \mu \mathrm{g}$ TMTD $\mathrm{ml}^{-1}$. Incubation was at $37^{\circ} \mathrm{C}$, with shaking for $32 \mathrm{~h}$, using $500 \mathrm{ml}$ Sakaguchi flasks. Strains: O, M910; ○, C912; O, C1001.

compounds unfavourable to growth. The chemicals tested were typical thiol-reactive agents $\left(\mathrm{HgCl}_{2}\right.$, iodoacetamide), a metal-chelating agent (8-hydroxyquinoline), an antibiotic (chloramphenicol) and others (mostly inhibitors of $\gamma$-glutamyltranspeptidase). As can be seen in Table 4, the $\gamma$-glutamylcysteine synthetase-deficient strain (C912) was highly susceptible to various inhibitors, with the exception of chloramphenicol, whereas the glutathione synthetase-deficient strain $(\mathrm{C} 1001)$ was somewhat more resistant to these compounds. The specific interactions of these compounds with glutathione were not elucidated in this study.

Figure 2 shows the change in viability of mutant and parental strains exposed to tetramethylthiuram disulphide (TMTD) and 8-hydroxyquinoline (8-HQ). A marked decrease in viability was observed for the $\gamma$-glutamylcysteine synthetase-deficient strain (C912). The addition of glutathione to the mixture with TMTD or 8-HQ protected the cells of strain C912.

Susceptibility to oxygen. Figure 3 shows the growth of mutant and parental strains in different volumes of minimal medium containing $10 \mu \mathrm{g} \mathrm{TMTD} \mathrm{m} \mathrm{T}^{-1}$. Growth of the parental strain (M910) was unaffected by the volume of the medium, whereas inhibition of the growth of the $\gamma$-glutamylcysteine synthetase-deficient strain (C912) increased as the volume of the medium decreased. The effect of the culture volume on growth was less severe for the glutathione synthetase-deficient mutant (C1001). 
DIS C USSION

Mutants of $E$. coli B deficient in glutathione biosynthesis were easily isolated by a previously described method (Murata et al., 1981). An alternative method for the isolation of such mutants, a colony colour technique, has been reported by Apontoweil \& Berends (1975). However, the application of their method is limited to bacterial strains with extremely low concentrations of intracellular thiol compounds other than glutathione. Cells containing larger quantities of thiol compounds will still produce a red colour even in the absence of glutathione. This is the case with $E$. coli $\mathrm{B}$, and thus the method is unsuitable for isolating glutathione biosynthesis-deficient mutants in this organism. Our method, using a cysteine auxotroph in combination with a methylglyoxal-resistant mutant, is simple and easy, and may be applied to all bacterial strains regardless of the intracellular content of thiol compounds.

Two types of mutants were isolated. Enzymic analysis showed that one type lacked $\gamma$-glutamylcysteine synthetase activity (C912 and C915) and the other lacked glutathione synthetase activity (C1001). The defect in glutathione biosynthesis was further supported by the fact that the mutants contained little glutathione. All other mutants obtained showed both $\gamma$-glutamylcysteine synthetase and glutathione synthetase activity: these may be the revertants of M910, a methylglyoxal-resistant strain which excretes glutathione into the growth medium (Murata et al., 1980).

The growth of the glutathione biosynthesis-deficient mutants in minimal medium was not significantly affected by glutathione deficiency. As originally suggested by Apontoweil \& Berends (1975) and by Fuchs \& Warner (1978), this indicates that glutathione is not specifically required for any process in the cells for their proliferation. This is of considerable interest, since glutathione represents approximately $40 \%$ of the total thiol compounds in $E$. coli $\mathrm{B}$ cells.

In agreement with the results of Apontoweil \& Berends (1975), glutathione was found to be a significant factor for the protection of cells exposed to toxic compounds. The mutant deficient in $\gamma$-glutamylcysteine synthetase activity was more susceptible to various inhibitors than either the parental strain or the mutant deficient in glutathione synthetase activity. It seems likely that $\gamma$-glutamylcysteine, a product of the $\gamma$-glutamylcysteine synthetase reaction, can substitute for glutathione in some, but not all, instances. This result suggests that the mutation was brought about only in the region of $g \operatorname{sh} A$, not in $g s h B$, though NTG treatment usually induces multiple mutations (Adelberg et al., 1965). Kosower \& Kosower (1969) showed that lysis occurs when a chemical challenge is made in the absence of glutathione and they termed this phenomenon the 'glutathione loss catastrophe'. The same phenomenon has been recognized by many other investigators, though the chemical interactions of glutathione with these substances remain obscure. The glutathione biosynthesis-deficient mutants were also susceptible to the amount of aeration, unlike the parental strains. In addition, a high susceptibility to lysozyme was found for the glutathione biosynthesis-deficient mutants (data not shown). Thus, glutathione may play an important role in the maintenance of the rigidity of cell walls.

We express our sincere thanks to Dr R. Hayashi, associate professor at the Research Institute for Food Science, Kyoto University, for kind advice on the preparation of $\gamma$-glutamylcysteine. We also thank N. Okamoto for her skilful assistance.

\section{REFERENCES}

Adelberg, E. A., Mandel, M. \& Chen, G. C. C. (1965). Optimal conditions for mutagenesis by $N$-methyl- $N^{\prime}$-nitro- $N$-nitrosoguanidine in Escherichia coli K-12. Biochemical and Biophysical Research Communications 18, 788-795.

A pontoweIL, P.\& Berends, W. (1975). Isolation and initial characterization of glutathione-deficient $\mathrm{mu}$ tants of Escherichia coli K-12. Biochimica et biophysica acta 399, 10-22.

Davis, B. D. \& Mingtoli, E. S. (1950). Mutants of Escherichia coli requiring methionine or vitamin $\mathrm{B}_{12}$. Journal of Bacteriology 60, 17-28. 
Ellman, G. L. (1959). Tissue sulfhydryl groups. Archives of Biochemistry and Biophysics 82, 70-77.

FUCHS, J. A. \& W ARNER, H. R. (1975). Isolation of an Escherichia coli mutant deficient in glutathione biosynthesis. Journal of Bacteriology 124, 140-148.

JACKSON, R. C. (1969). Studies in the enzymology of glutathione metabolism in human erythrocytes. Biochemical Journal 111, 309-315.

Kosower, E. M. \& Kosower, N. S. (1969). Lest I Forget Thee, Glutathione ... Nature, London 224, 117-120.

Kosower, N. S., Kosower, E. M., Wertheim, B. \& Correa, W. S. (1969). Diamide, a new reagent for the intracellular oxidation of glutathione to the disulfide. Biochemical and Biophysical Research Communications 37, 593-596.

Mooz, B. D. \& Meister, A. (1967). Tripeptide (glutathione) synthesis, purification, properties, and mechanism of action. Biochemistry 6, 1722-1734.

Murata, K., Kato, J. \& Chibata, I. (1978). Continuous production of glutathione by im- mobilized Saccharomyces cerevisiae cells. European Journal of Applied Microbiology and Biotechnology 6, 23-27.

Murata, K., Tani, K., Kato, J. \& Chibata, I. (1980). Excretion of glutathione by methylglyoxalresistant Escherichia coli. Journal of General Microbiology 120, 545-547.

Murata, K., Tani, K., Kato, J. \& Chibata, I. (1981). Isolation of Escherichia coli B mutants deficient in glutathione biosynthesis. Agricultural and Biological Chemistry 45, 2131-2132.

Srivastava, S. K., Awasthi, Y. C. \& Beutler, E. (1974). Useful agents for the study of glutathione metabolism in erythrocytes. Biochemical Journal 139, 289-295.

Strumeyer, D. \& Block, K. (1962). $\gamma$-L-GlutamylL-cysteine from glutathione. Biochemical Preparations 9, 52-54.

SzYBALSKY, W. \& Bryson, V. (1952). Genetic studies on microbial cross resistance to toxic agents. Journal of Biological Chemistry 64, 489-499. 